\title{
Gauging the Threat: The First Population Estimate for White Sharks in South Africa Using Photo Identification and Automated Software
}

\author{
Alison V. Towner ${ }^{1,2}$, Michelle A. Wcisel ${ }^{1,2}$, Ryan R. Reisinger ${ }^{3}$, David Edwards ${ }^{1}$, Oliver J. D. Jewell ${ }^{1,3 *}$ \\ 1 Dyer Island Conservation Trust, Great White House, Kleinbaai, Gansbaai, South Africa, 2 Department of Zoology, University of Cape Town, Rondebosch, South Africa, \\ 3 Mammal Research Institute, Department of Zoology and Entomology, University of Pretoria, Hatfield, South Africa
}

\begin{abstract}
South Africa is reputed to host the world's largest remaining population of white sharks, yet no studies have accurately determined a population estimate based on mark-recapture of live individuals. We used dorsal fin photographs (fin IDs) to identify white sharks in Gansbaai, South Africa, from January 2007 - December 2011. We used the computer programme DARWIN to catalogue and match fin IDs of individuals; this is the first study to successfully use the software for white shark identification. The programme performed well despite a number of individual fins showing drastic changes in dorsal fin shape over time. Of 1682 fin IDs used, 532 unique individuals were identified. We estimated population size using the openpopulation POPAN parameterisation in Program MARK, which estimated the superpopulation size at 908 ( $95 \%$ confidence interval 808-1008). This estimated population size is considerably larger than those described at other aggregation areas of the species and is comparable to a previous South African population estimate conducted 16 years prior. Our assessment suggests the species has not made a marked recovery since being nationally protected in 1991. As such, additional international protection may prove vital for the long-term conservation of this threatened species.
\end{abstract}

Citation: Towner AV, Wcisel MA, Reisinger RR, Edwards D, Jewell OJD (2013) Gauging the Threat: The First Population Estimate for White Sharks in South Africa Using Photo Identification and Automated Software. PLoS ONE 8(6): e66035. doi:10.1371/journal.pone.0066035

Editor: Danilo Russo, Università degli Studi di Napoli Federico II, Italy

Received February 16, 2013; Accepted May 1, 2013; Published June 12, 2013

Copyright: (c) 2013 Towner et al. This is an open-access article distributed under the terms of the Creative Commons Attribution License, which permits unrestricted use, distribution, and reproduction in any medium, provided the original author and source are credited.

Funding: This work was supported by Marine Dynamics Shark Tours (www.sharkwatchsa.com) and the Dyer Island Conservation Trust (www.dict.org.za); these organizations are supported by donations from tourists and VW South Africa (www.vw.co.za). Marine Dynamics provided the platform to collect data from its shark cage diving trips and has also contributed to the study costs of AT, OJ and MW's Masters research. These authors continue to gain financial support from Marine Dynamics as they pursue future academic goals. The funders had no role in study design, data collection and analysis, decision to publish, or preparation of the manuscript. This does not alter the authors' adherence to all the PLOS ONE policies on sharing data and materials.

Competing Interests: The authors have declared that no competing interests exist.

*E-mail: oliverjewell@gmail.com

\section{Introduction}

White sharks Carcharodon carcharias are widely distributed apex predators which are known to undertake extensive oceanic migrations [1-6]. They also exhibit semi-annual site fidelity to predictable coastal locations often associated with pinniped colonies, effectively pooling individuals to locations, or aggregation areas, accessible to researchers [7-9]. These aggregation areas have provided a unique opportunity to estimate white shark populations utilising mark-recapture methods $[9,10]$.

Photo Identification (photo ID) has been developed as a noninvasive method of mark and recapture in which distinctive features of an individual can be used to recognise it against the rest of the population during different samples, over extensive time periods. This method is particularly appropriate when examining vulnerable species or populations, from invertebrates [11,12] to tigers [13], marine mammals [14-16] and sharks [17-19]. The first dorsal fin of white sharks is often characterised by distinctive shapes, notches, scaring and pigmentation patterns, which can be used to recognise individuals over many years [7,19]. From such photo ID data, mark recapture methods can be applied to estimate population sizes, given that the model's basic assumptions are met adequately $[14,20]$.
Previous white shark population estimates suggest that white shark numbers are small relative to other apex predators [20]. Nasby-Lucas \& Domeier [9] identified a minimum of 142 individual white sharks using photographic identification at Guadalupe Island (GI) from 2001-2009. Chapple et al. [10] used mark recapture with a closed population model and estimated the regional population of white sharks in California to be 219 animals. However Sosa-Nishizaki et al. [20] and Nasby-Lucas \& Domeier [9] contest this estimate on the basis that the use of a closed model was inappropriate, there was no account for inshore recruitment [21,22], a lack of sampling from Año Nuevo Island (a major aggregation site for Californian white sharks) [23] and an insufficient sampling period for the methods to reflect appropriate trends. Cliff et al. [24] used mark and recapture of white sharks tagged with spaghetti tags that were captured and killed in the KwaZulu-Natal (KZN) Sharks Board nets to estimate a population of 1279 (CV 24\%) between Struisbaai, Western Cape and Richards Bay, KZN. The weakness of this method, however, was that the sharks used for the estimate were killed and were then no longer part of the population.

Few studies have attempted to estimate the South African population using mark and recapture techniques of living individuals [25]. The study site of Gansbaai was selected to make a first estimate of the current population of white sharks in the 


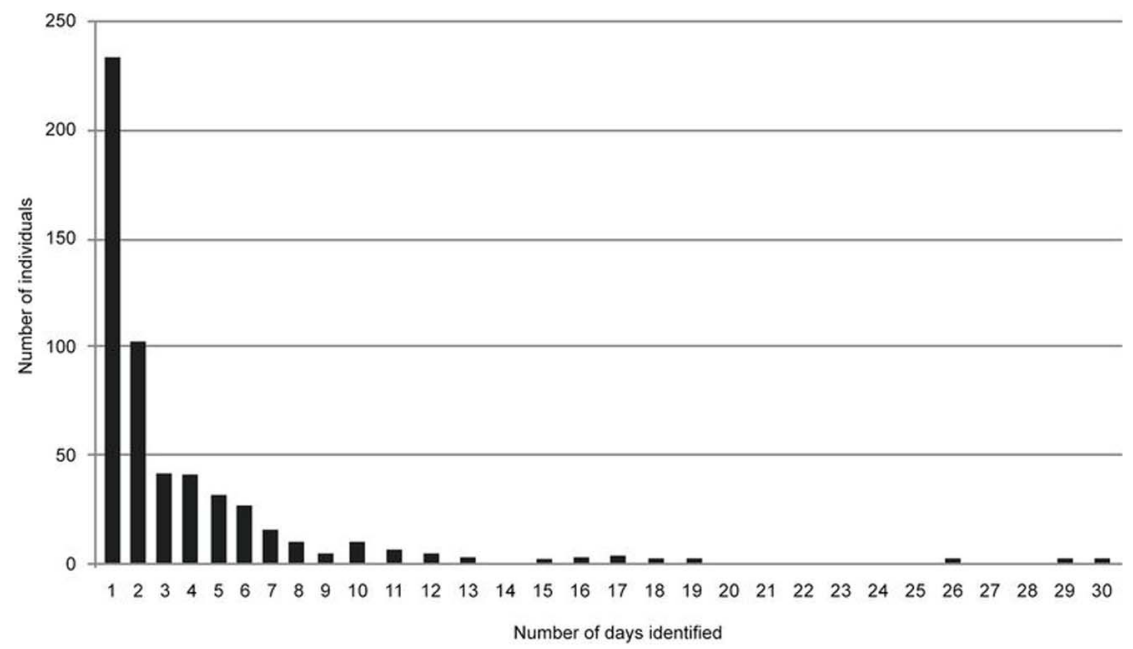

Figure 1. Sighting frequency distribution of photographically identified white sharks in the Gansbaai region (2007-2011). doi:10.1371/journal.pone.0066035.g001

region. Gansbaai is a world-recognised white shark aggregation site and is the only location in the world where cage diving trips operate daily, weather permitting [26]. Thus, this aggregation site provided an ideal area to collect dorsal fin images of a range of age classes and both sexes without seasonal paucities. Additionally, several individual white sharks from this region have been identified at other aggregation sites, with connectivity documented between False Bay, Mossel Bay, KwaZulu Natal, and Western Australia [1,19,27]. This suggests that Gansbaai is a major aggregation area for white sharks in the Southern African region allowing for an accurate population estimate from a single site.

\section{Methods}

We encountered white sharks at two aggregation areas in Gansbaai (Geyser Rock and Joubertsdam). Trips were permitted by the Department of Environmental Affairs, Oceans \& Coasts (formerly operating under Marine and Coastal Management); data collection was un-invasive and required no further ethical clearance. We attracted sharks to one of two cage diving vessels run by Marine Dynamics shark tours with a fish bait, seal decoy, and a scent trail created by a mixture of fish products and sea water. Tours were weather dependent and biased towards areas of high white shark abundance. We obtained images of white shark dorsal fins during 1647 trips coinciding with ca. 4120 hours of sampling effort $(\sim 2.5$ hours average $)$ from January 2007 December 2011.

We imported dorsal fin images into Picasa, a photograph editing programme (picasa.google.com). Images were organised by date, cropped and assigned a 1-6 quality ranking defined in Gowans \& Whitehead [28]. A ranking of 6 is considered to be a fin ID of the highest quality, i.e. the fin is entirely clear of the water, square to the camera, with good focus, lighting and adequate zoom. Q5 is considered high quality with only one of the previous requirements in Q6 lacking. The Q ranking decreases as the quality of photo ID decreases. We found that only photographs $Q^{4}$ and higher provided sufficient information to recognise individuals and allow "recapture" between sightings. Such photographs (n = 1683) were then imported into DARWIN dorsal fin ID software [29]. Each dorsal fin was traced and assigned a fixed spacing of points along

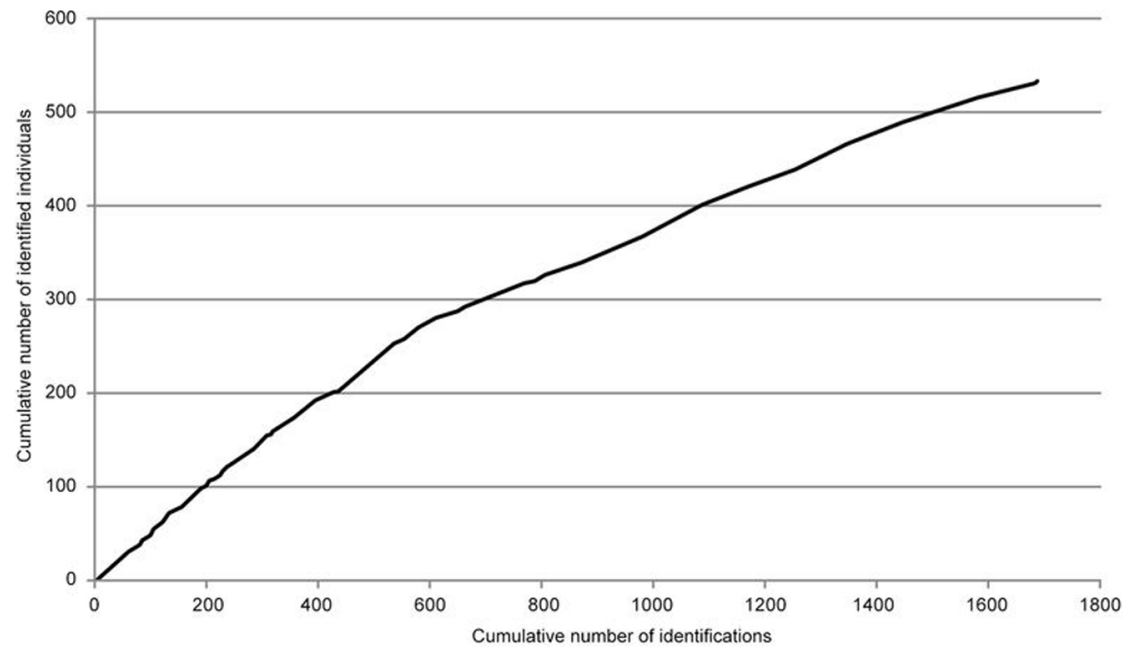

Figure 2. Discovery curve for photographically identified white sharks in the Gansbaai region (2007-2011). doi:10.1371/journal.pone.0066035.g002 
Table 1. Model choice criteria and abundance estimates $(N)$ for four models tested in a mark-recapture analysis of individual sighting histories of white sharks in the Gansbaai region (2007-2011), using the open-population POPAN parameterisation in Program MARK.

\begin{tabular}{|c|c|c|c|c|c|c|c|c|c|}
\hline \multirow[t]{2}{*}{ Model } & \multirow[t]{2}{*}{ QAIC $_{c}$} & \multirow[t]{2}{*}{$\Delta$ QAIC $_{\mathrm{c}}$} & \multirow[t]{2}{*}{$\begin{array}{l}\text { Model } \\
\text { Likelihood }\end{array}$} & \multirow[t]{2}{*}{ Parameters } & \multicolumn{2}{|c|}{ Quasi Deviance N } & \multicolumn{2}{|c|}{ 95\% Confidence Interval } & \multirow[t]{2}{*}{ CV } \\
\hline & & & & & & & Lower & Upper & \\
\hline ф. $P_{t} b_{t}$ & 1719.88 & - & 1 & 35 & 0 & 908 & 808 & 1008 & 0.056 \\
\hline$\phi_{t} p_{t} b_{t}$ & 1746.38 & 26.50 & 0 & 53 & 0 & 823 & 717 & 929 & 0.066 \\
\hline$\phi$. p. $b_{t}$ & 1791.19 & 71.31 & 0 & 14 & 0 & 950 & 853 & 1048 & 0.052 \\
\hline$\phi_{\mathrm{t}} \mathrm{p}, \mathrm{b}_{\mathrm{t}}$ & 1802.91 & 83.03 & 0 & 33 & 0 & 956 & 851 & 1062 & 0.056 \\
\hline
\end{tabular}

See text for criteria.

doi:10.1371/journal.pone.0066035.t001

the leading and trailing edges. This trace was compared to the entire catalogue and ranked by probability of a match. Final matching was confirmed by eye as pigmentation, scarring, freckles or fin changes over time can be accounted for. Fins that could not be matched to a fin already existing in the catalogue were assigned a unique ID code corresponding with the first date of sighting and fin order of that trip (e.g., 20110601-2 for the second shark on 1 June 2011) and then added. Inputted fins that matched a catalogue fin were assigned the ID code of that matched individual and also added. Data from DARWIN was exported to MS Excel where individual abundance and occasionality could be assessed.

We performed mark-recapture analyses of the sighting histories of recognisable individuals using Program MARK [30], which uses Maximum Likelihood models to estimate population parameters [31]. We pooled photographic sightings into quarterly sampling intervals after comparing the results for various sampling intervals. Population closure was not a reasonable assumption and therefore we used the open-population POPAN parameterisation $[32,33]$ to estimate population parameters. In this parameterisation, $\mathcal{N}$ represents the size of a superpopulation; which can be thought of as either the total number of individuals available for observation at any time during the study or as the total number of animals ever in the sampled area between the first and last occasion of the study [34]. The parameter $\Phi$ denotes apparent survival rate, $p$ is the probability of observation and $b$ represents the probability that an animal from the superpopulation enters the sub-population (sub-population referring to the animals occurring in the study area). In model notation, the subscripts $t$ and. represent time-dependent and constant parameters, respectively, [35] and the initial analysis is based on the fully time-dependent/ Cormack-Jolly-Seber (CJS) model $\left\{\Phi_{t} p_{t} b_{t}\right\}$. The first step in the analysis involves Goodness-of-Fit (GOF) tests for the CJS model using Program RELEASE [36] to validate model assumptions. Models were constructed for combinations of time-dependence and consistency for each parameter and the most appropriate model was selected using the small sample corrected Akaike Information Criterion $\left(\mathrm{AIC}_{\mathrm{c}}\right)$ [37]. Based on the GOF results of TEST 2+ TEST 3 in RELEASE a post-hoc variance inflation factor $(\hat{c})$ may be estimated to adjust for extra-binomial variation in the data, resulting in a quasi-Akaike Information Criterion $\left(\mathrm{QAIC}_{\mathrm{c}}\right)$.

\section{Results}

We identified 532 unique individuals which were included in the population size analyses. Figure 1 shows the sighting frequency distribution of these animals and figure 2 shows the discovery curve - or cumulative number of identified individuals - as the study progressed. Of the eight models tested, two did not converge. Both of these contained $b$. (constant probability of entry); the two other models containing $b$. did converge, but had very large quasi-deviances, indicating that constant probability of entry was not a reasonable assumption. For the remaining four models, model choice criteria as well as abundance estimates and parameter estimates are shown in Table 1. Based on the result of TEST 2+ TEST 3 in Program RELEASE (Table 2), a variance inflation factor of $\hat{c}=1.36$ was estimated and applied, indicating only slight over dispersion in the data [31]. According to the QAIC $_{\mathrm{c}}$ scores, model $\left\{\boldsymbol{\phi} . p_{\mathrm{t}} b_{\mathrm{t}}\right\}$ (constant survival, time-varying probability of capture and probability of entry) was the most parsimonious. This model estimated the superpopulation size at 908 individuals $(95 \%$ confidence interval $=808-1008)$. No models had a $\triangle$ QAIC $_{\mathrm{c}}<2$ units, which would have indicated that they were also likely [37]. Some violation of underlying openpopulation mark-recapture assumptions was evident (Table 2). Significance of TEST $3(p=0.006)$ and one of its components (3.SR; $p=0.0001$ ) indicate unequal survival probabilities among photographically captured animals.

\section{Discussion}

Unlike Chapple et al. [10], we found the computer program DARWIN suitable for matching and cataloguing white shark dorsal fins within a large dataset. While DARWIN had infrequent considerable errors in ranking fins, we considered this flaw minor when compared to the human error of matching by eye alone.

Table 2. Program RELEASE goodness-of-fit results for the fully time-dependent/Cormack-Jolly-Seber model tested in a mark-recapture analysis of individual sighting histories of white sharks in the Gansbaai region (2007-2011), using the open-population POPAN parameterisation in Program MARK.

\begin{tabular}{lllll}
\hline Test & $\mathbf{X}^{\mathbf{2}}$ & $\mathbf{D f}$ & $\mathbf{P}$ & $\hat{\mathbf{C}}$ \\
\hline 2 & 51.86 & 47 & 0.2900 & - \\
3 & 56.75 & 33 & $\mathbf{0 . 0 0 6 2}$ & - \\
$3 . \mathrm{SR}$ & 48.68 & 18 & $\mathbf{0 . 0 0 0 1}$ & - \\
$3 . \mathrm{SM}$ & 8.07 & 15 & 0.9209 & - \\
$2+3$ & 108.61 & 80 & $\mathbf{0 . 0 1 8 4}$ & 1.36 \\
\hline
\end{tabular}

Shaded $p$-values are significant at $\alpha=0.05$

doi:10.1371/journal.pone.0066035.t002 


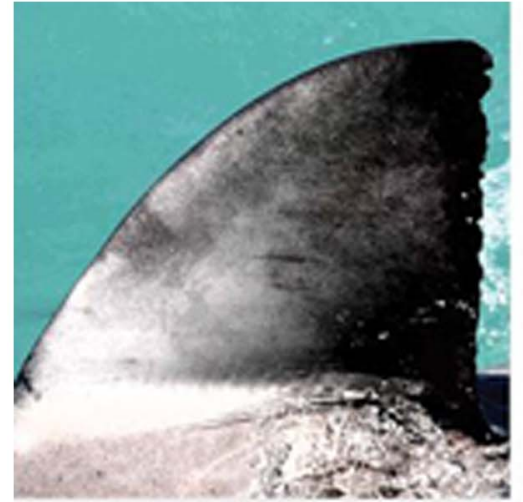

08.01 .2007

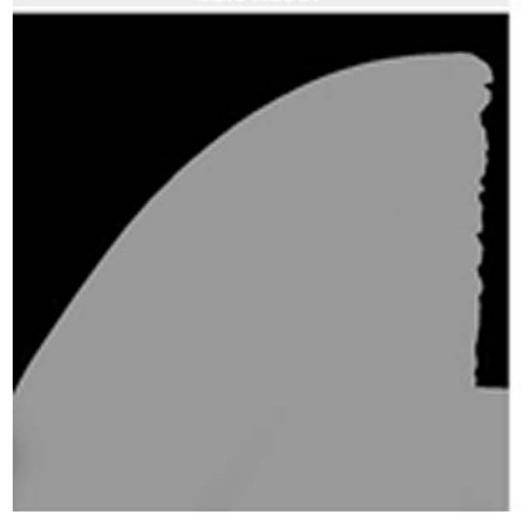

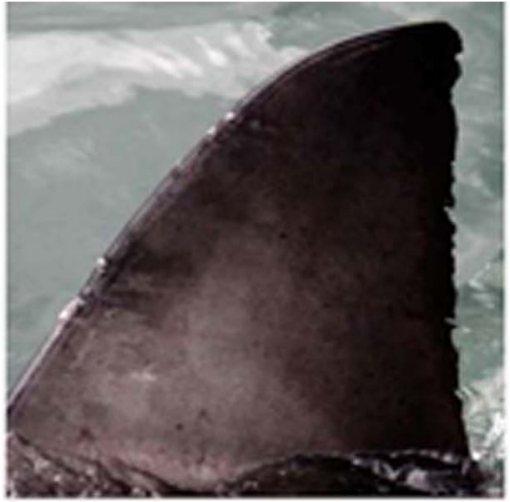

09.11 .2009

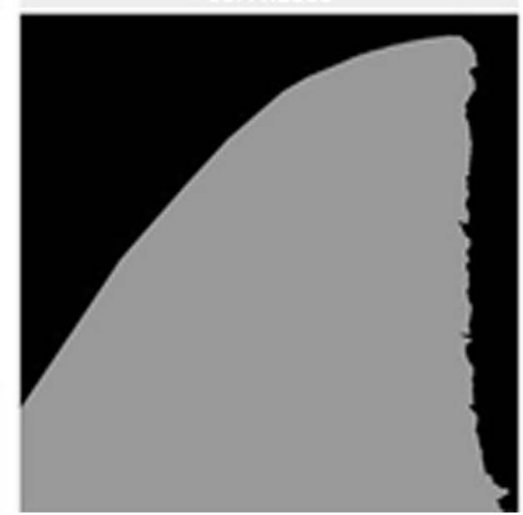

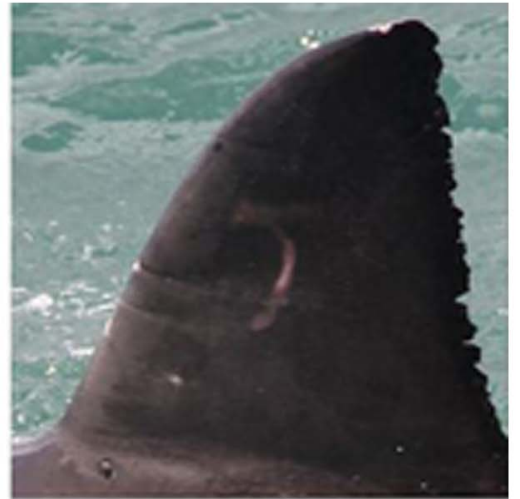

17.08 .2011

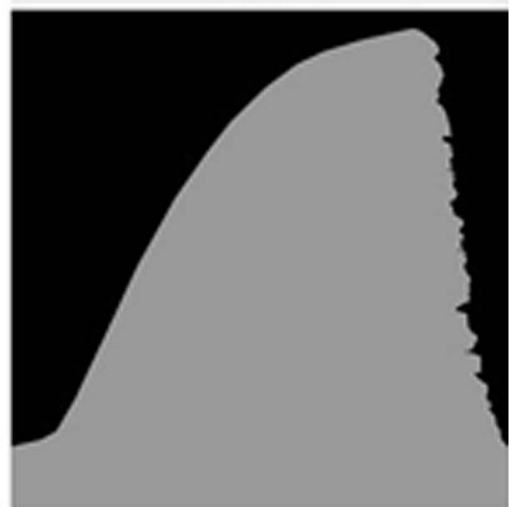

Figure 3. Study animal 'Darwin', photographed numerous times from 2007-2011. This fin clearly demonstrates how small additions/changes to notches occurring on the back of the fin can distinguish it from early photos, increasing the probability of later fin IDs being identified as multiple sharks. doi:10.1371/journal.pone.0066035.g003

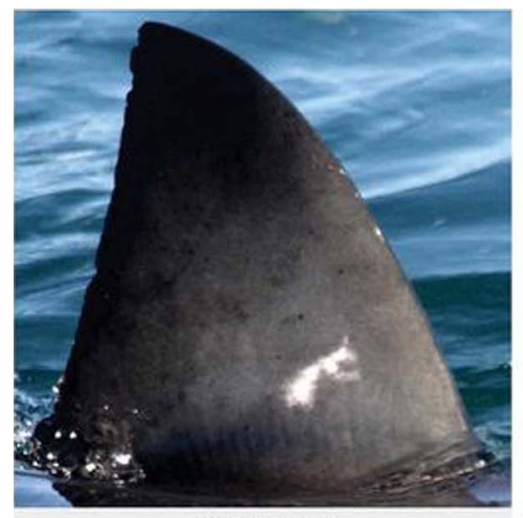

02.03.2007

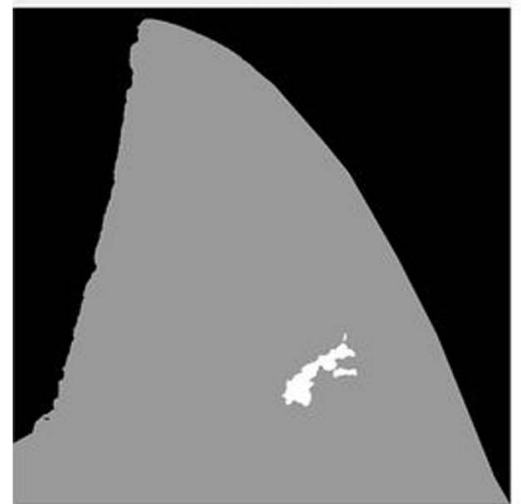

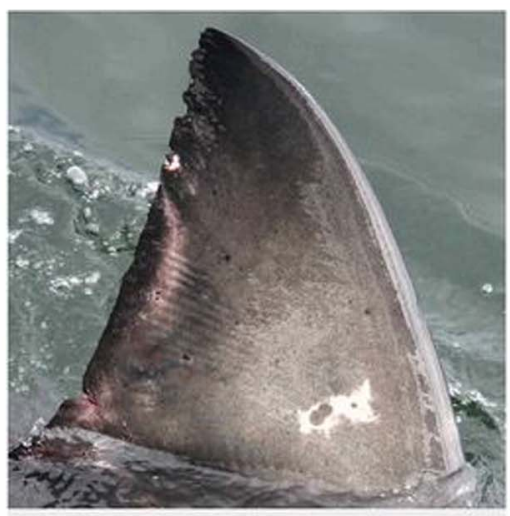

23.03.2009

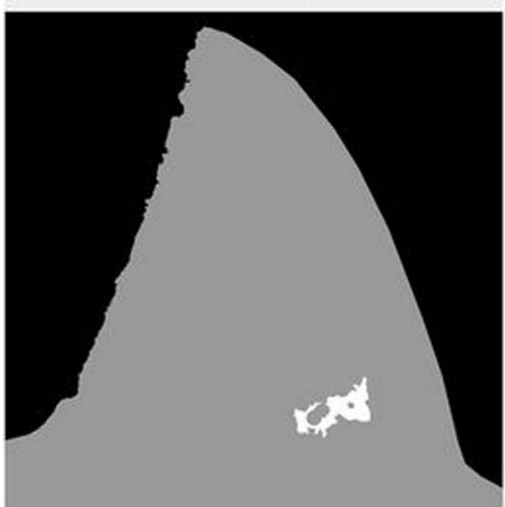

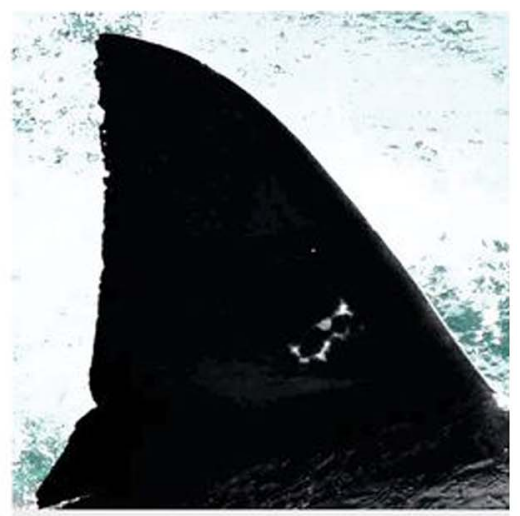

21.03.2011

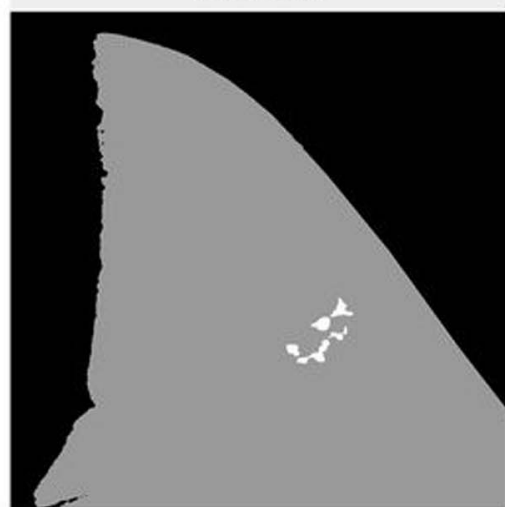

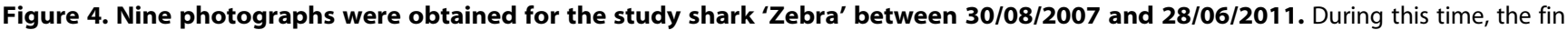
sustained significant damage to both its front and back areas, altering its profile. This affects the number of notches down the back of the fin. doi:10.1371/journal.pone.0066035.g004 


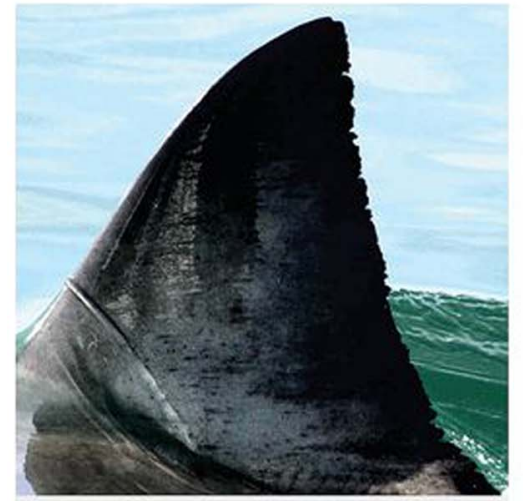

30.08.2007

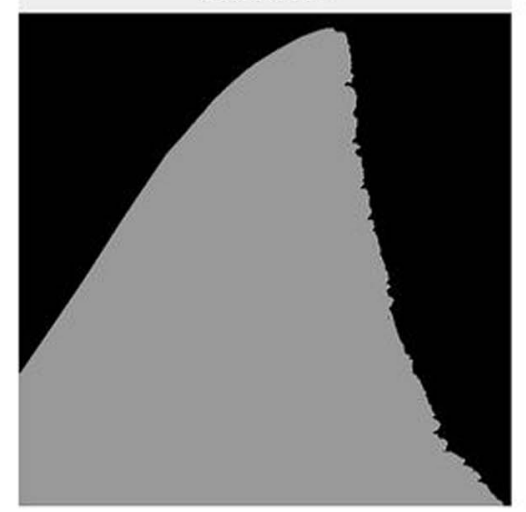

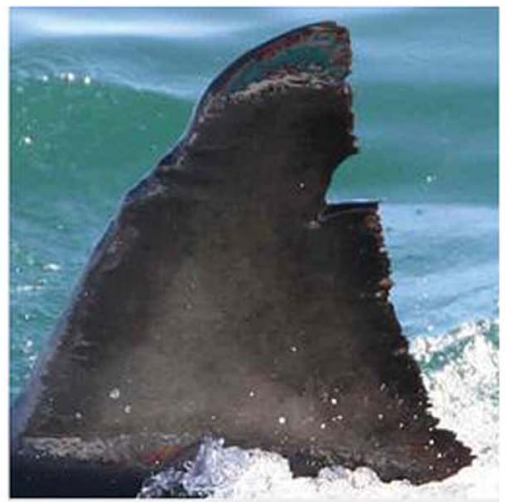

13.05.2011
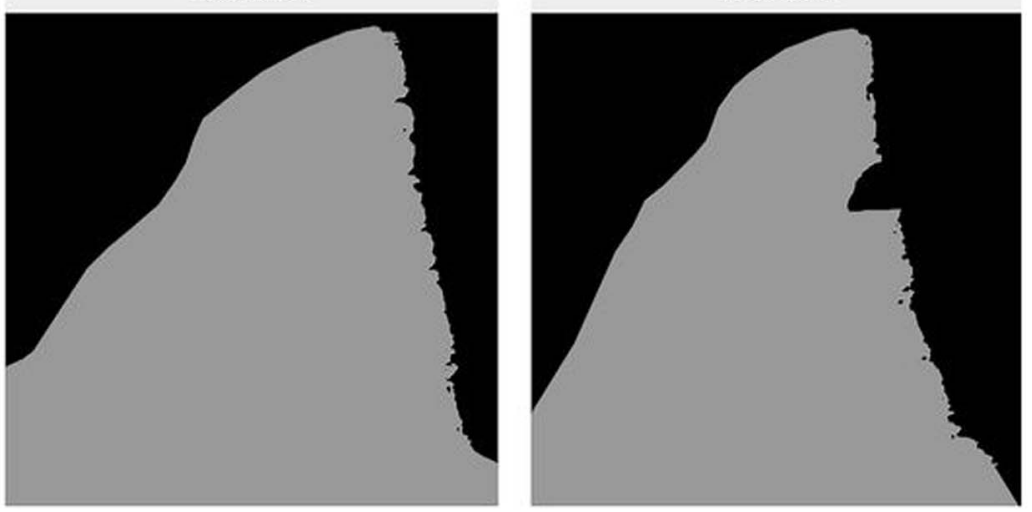

Figure 5. Study shark 'Vindication', one of the few sharks to be photographed at least once in every year from $2007-2011$. Vindication features numerous, subtle changes in harsh contrast to the minimal, significant scars on the other examples above. On Vindication's dorsal fin, white pigmentation 'roise' changes occurred slowley over time. doi:10.1371/journal.pone.0066035.g005

Confirming this, we found that many dorsal fin trailing edges changed dramatically from one sighting to another, an aspect we were only able to detect as DARWIN accounts for more than just the notches in the trailing edge of the fin. In most cases, the leading edge and top quarter of the fin exhibited very little change (Fig. 3), whereas the bottom $3 / 4$ of the fin can be unrecognisable between sightings (Fig. S1). We also observed changes to entire fin shapes (Fig. 4). We were able to track these changes over time due to consistent sampling effort, allowing us to consider fresh damage or changes to fins when cataloguing. Without consistent effort, it is possible that individual fins which changed would not be successfully matched to the same individual shark, thus fin IDs from the same shark over time can be counted as multiple individuals resulting in an over-estimation of animals. In addition, pigmentation patterns, or 'rosies' [26,38], were found to change over time in most cases (Fig. 5) which is similar to the pigmentation changes that have been described to occur around the lower caudal areas of white sharks in south Australia [38]. The amount of fin degradation in the lower quarters of the fin or changes in pigmentation patterns do not seem to relate to the size/class of the individual upon first sighting. However, presence of copepod parasites along the trailing edge of the fin did seem to lead to initial notch formation. These changes in fin morphology highlight that previously proposed methods based on counting fin notches (i.e. 'The Rutzen Method' in O'Connel et al. [39]; Andriotti et. al. [40]) are unreliable for long-term mark-recapture analysis.

A common bias in many mark-recapture studies is capture heterogeneity [41]. In our study we attracted sharks by bait, thus some individuals may have become 'trap happy' or 'trap shy' over time [41]. This may lead to bias on estimates, but the effects of baiting on individual sharks remains undetermined [27,42]. To address this, future work should focus on the effects of shyness or boldness in individual white sharks and assess whether they are more or less likely to appear close to a baiting vessel over time as well as incorporating such heterogeneity in behaviour in population size estimation.

Our population estimate for white sharks in Gansbaai is considerably higher than those obtained for other aggregation areas $[9,10,20]$, supporting claims that South Africa has the largest remaining population of coastal white sharks [25]. Our estimate is comparable to that given by Cliff et al. [24]. This is not surprising, as most white sharks that utilise Gansbaai aggregations also move into KZN shark netted areas [43]. Unfortunately, dorsal fin photos of white sharks killed in KZN shark nets were not collected during this study period, therefore we cannot compare the living fin-ID population of Gansbaai to the culled population in KZN [24,44]. There are 11 years between the end of Cliff et al.'s [24] data collection and the beginning of sampling in Gansbaai (this study). This suggests white shark numbers have not shown marked recovery from; 1) the deployment of shark nets and drum lines along the KZN coastline in 1952, which are still in place to date [44]; 2) the heavy fishing pressures white sharks experienced in the 1970's and 80's [8]; and 3) a lack of protection in neighbouring Mozambique [43]. Despite the species being protected since 1991 [8], such a low estimate and lack of recovery rate suggests the Southern African white shark is not receiving adequate protection for population growth. These results highlight the need for 
effective protective measures within the entire home range of the Southern African white shark.

\section{Supporting Information}

Figure S1 Study shark 'Demon', demonstrating signficant change in the lower three quarters of the trailing edge. Despite having a large injury to the trailing ege of the dorsal fin, the fin identification can still be matched by using the shape of the leading edge and the top quarter of the fin.

(TIF)

\section{Acknowledgments}

Many thanks to all staff, crew and volunteers at Marine Dynamics who made this work possible. Special thanks to Wilfred Chivell whose passion,

\section{References}

1. Bonfil R, Meÿer M, Scholl MC, Johnson R, O'Brien S, et al. (2005) Transoceanic migration, spatial dynamics, and population linkages of white sharks. Science 310: 100-103.

2. Bruce BD (2008) The biology and ecology of the White Shark, Carcharodon carcharias. In: Sharks of the Open Ocean: Biology, Fisheries \& Conservation (eds. MD Camhi, EK Pikitch, EA Babcock), 69-81 Blackwell Publishing, Oxford, United Kingdom.

3. Domeier ML, Nasby-Lucas N (2008) Migration patterns of white sharks Carcharodon carcharias tagged at Guadalupe Island, Mexico, and identification of an eastern Pacific shared offshore foraging area. Mar Ecol Prog Ser 370: 221237.

4. Duffy CAJ, Francis MP, Manning MJ, Bonfil R (2012) Regional population connectivity, oceanic habitat, and return migration revealed by satellite tagging of white sharks, Carcharodon carcharias, at New Zealand aggregation sites. In: Global Perspectives on the Biology and Life History of the White Shark (ed. ML Domeier), 147-158. CRC Press, Boca Raton, Florida.

5. Domeier ML (2012) A new life history hypothesis for white sharks in the Northeastern Pacific In: Global Perspectives on the Biology and Life History of the White Shark (ed. ML Domeier), 199-223. CRC Press, Boca Raton, Florida.

6. Weng KC, Boustany AM, Pyle P, Anderson SD, Brown A, et al. (2007) Migration and habitat of white sharks (Carcharodon carcharias) in the eastern Pacific Ocean. Mar Biol 152(4): 877-894.

7. Anderson SD, Chapple TK, Jorgensen SJ, Klimley AP, Block BA (2011) Longterm identification and site fidelity of white sharks, Carcharodon carcharias, off California using dorsal fins. Mar Biol 158: 1233-1237.

8. Compagno LJV (1991) Government protection for the great white sharks (Carcharodon carcharias) in South Africa. S Afri J Sci 87: 2845-2846.

9. Nasby-Lucas N, Domeier ML (2012) Use of photo identification to describe a white shark aggregation at Guadalupe Island, Mexico. In: Global Perspectives on the Biology and Life History of the White Shark (ed. ML Domeier), 381-391. CRC Press, Boca Raton, Florida.

10. Chapple TC, Jorgensen SJ, Anderson SD, Kanive PE, Klimley AP, et al. (2011) A first estimate of white shark, Carcharodon carcharias, abundance off Central California. Biol Lett 7: 581-583.

11. Caci G, Biscaccianti AB, Cistrone L, Bosso L, Garonna AP, et al. (2013) Spotting the right spot: computer-aided individual identification of the threatened cerambycid beetle Rosalia alpina. Journal of Insect Conservation. doi:10.1007/s10841-013-9561-0.

12. Huffard CL, Caldwell RL, DeLoach N, Gentry DW, Humann P, et al. (2008) Individually unique body color patterns in Octopus (Wunderpus photogenicus) allow for photoidentification. PLoS ONE 3(11): e3732. doi:10.1371/journal. pone.0003732.

13. Hiby L, Lovell P, Patil N, Samba Kumar N, Gopalaswary AM, et al. (2009) A Tiger cannot change its stripes: using three-dimensional model to match images of living tigers and tiger skins. Biol lett 5: 383-386.

14. Reisinger RR, de Bruyn PJN, Bester MN (2011) Abundance estimate of killer whales at subantarctic Marian Island. Aquat Biol 12: 177-185.

15. Langtimm CA, Beck CA, Edwards HH, Fick-Child KJ, Ackerman BB, et al. (2004) Survival estimates of Florida manatees from photo-identification of individuals. Mar Mamm Sci: 20: 438-463.

16. Reisinger RR, Karczmarski L (2010) Population size estimate of Indo-Pacific bottlenose dolphins in the Algoa Bay region, South Africa. Mar Mam Sci 26(1): 86-97.

17. Bansemer CS, Bennett MB (2009) Reproductive periodicity, localised movements and behavioural segregation of pregnant Carcharias taurus at Wolf Rock, Southeast Queensland, Australia. Mar Ecol Prog Ser 374: 215-227.

18. Speed CW, Meekan MG, Bradshaw CJA (2007) Spot the match - wildlife photoidentification using information theory. Front Zool 4: 2. doi: 10.1186/ 1742-9994-4-2. drive, and threats inspired and motivated this work. Thanks also to Mike Gibbs and others at the Dyer Island Conservation Trust and VW South Africa for their support and sponsorship. Thanks to all that tirelessly helped with cataloguing, cropping, ranking and inputting fins, namely: Nick Jones, Matt Nicholson, Ellie McLennan, Tami Kaschke, Blair Ranford and Tess Mahoney among others.

\section{Author Contributions}

Wrote the paper: OJ MW AT RR DE. Initiated the project: AT MW OJ. Collected fin ID photographs: AT OJ MW. Determined methodology for processing fin IDs: MW. Cataloged and cropped photos in Picasa: MW DE OJ AT. Processed fin IDs in DARWIN: DE MW. Ran MARK analysis: RR. Produced figures: DE RR. Wrote the paper: OJ MW AT RR DE.

19. Jewell OJD, Wcisel MA, Gennari E, Towner AV, Bester MN, et al. (2011) Effects of Smart Position Only (SPOT) tag deployment on white sharks Carcharodon carcharias in South Africa. PLoS ONE 6(11): e27242.

20. Sosa-Nishizaki O, Morales-Bojorquez E, Nasby-Lucas N, Onate-Gonzalez EC, Domeier ML (2012) Problems with photo identification as a method of estimating abundance of white sharks, Carcharodon carcharias an example from Guadalupe Island, Mexico. In: Global Perspectives on the Biology and Life History of the White Shark (ed. ML Domeier), 393-404. CRC Press, Boca Raton, Florida.

21. Weng KC, O'Sullivan JB, Lowe CG, Winkler CE, Dewar H, et al. (2007) Movements, behaviour and habitat preferences of juvenile white sharks Carcharodon carcharias in the eastern Pacific. Mar Ecol Prog Ser 388: 211-224.

22. Lowe CG, Blausius ME, Jarvis ET, Mason TJ, Goodmanlowe GD, et al. (2012) Historic fisheries interaction with white sharks in the Southern California Bight. In: Global Perspectives on the Biology and Life History of the White Shark (ed. ML Domeier), 169-185 CRG Press, Boca Raton, Florida.

23. Klimley AP, Le Boeuf BJ, Cantara KM, Richert JE, Davis SF et al. (2001) The hunting strategy of white sharks (Carcharodon carcharias) near a seal colony. Mar Biol 138: 617-636.

24. Cliff G, van der Elst RP, Govender A, Witthuhn TK, Bullen EM (1996) First estimates of mortality and population size of white sharks on the South African coast. In: Great White Sharks: The Biology of Carcharodon carcharias (eds. AP Klimley, DG Ainley). Academic Press, San Diego, California, 393-400.

25. Dudley SFJ (2012) A review of research on the white shark, Carcharodon carcharias (Linnaeus), in Southern Africa. In: Global Perspectives on the Biology and Life History of the White Shark (ed. ML Domeier), 511-532. Boca Raton: CRC Press, Florida.

26. Towner AV (2012) Great white sharks Carcharodon carcharias in Gansbaai, South Africa: Environmental influences over time, 2007-2011. MSc Thesis, University of Cape Town.

27. Johnson R, Kock A (2006) South Africa's White Shark cage-diving industry - is their cause for concern? In Nel DC \& Peschak TP (eds) Finding a balance: White shark conservation and recreational safety in the inshore waters of Cape Town, South Africa; proceedings of a specialist workshop. WWF South Africa Report Series - 2006/Marine/001.

28. Gowens S, Whitehead H (2001) Photographic identification of northern bottlenose whales (Hyperoodon ampullatus): sources of heterogeneity from natural marks. Mar. Mam. Sci. 17(1): 76-93.

29. Stanley R (1995) DARWIN: Identifying Dolphins from Dorsal Fin Images. Senior Thesis, Eckerd College.

30. White GC, Burnham KP (1999) Program MARK: survival estimation from populations of marked animals. Bird St Supp 46: 120-138.

31. Cooch E, White G (eds) (2009) Program MARK: a gentle introduction, 8th edn. Available: http://www.phidot.org/software/mark/docs/book.

32. Schwarz CJ, Arnason AN (1996) A general methodology for the analysis of capture-recapture experiments in open populations. Biomet 52: 860-873.

33. Schwarz GJ, Arnason AN (2009) Jolly-Seber models in MARK. In: MARK: a gentle introduction (eds. E. Cooch \& G. White) Program, 8th edn. Available: http://www.phidot.org/software/mark/docs/book.

34. Nichols JD (2005) Modern open-population capture-recapture models. In: Handbook of capture-recapture analysis (eds. SC Amstrup, TL, McDonald, BFJ Manly), 88-123. Princeton University Press, Princeton.

35. Lebreton JD, Burnham KP, Clobert J, Anderson DR (1992) Modeling survival and testing biological hypotheses using marked animals: A unified approach with case studies. Ecol Monog 62: 67-118.

36. Burnham KP, Anderson DR, White GC, Brownie CR, Pollock KH (1987) Design and analysis methods for fish survival experiments based on releaserecapture. Am Fish Soc Monog 5.

37. Burnham KP, Anderson DR (1998) Model selection and inference: a practical information-theoretic approach. Springer-Verlag, New York. 
38. Robbins R, Fox A (2013) Further evidence of pigmentation change in white sharks, Carcharodon carcharias. Mar Freshw Res 63 (12): 1215-1217.

39. O'Connell C, Andreotti S, Rutzen M, Me?er M, He P (2012) The use of permanent magnets to reduce elasmobranch encounter with a simulated beach net. 2. The great white shark (Carcharodon carcharias). J Oc Cost Manag. Available: http://dx.doi.org/10.1016/j.ocecoaman.2012.11.006.

40. Andriotti S, Rutzen M, Meÿer M, Oosthuizen H, Herbst B, et al. (2012) The Rutzen Method. J Exp Mar Biol Ecol Cited in O'Connell et al. 2012 Available: http://dx.doi.org/10.1016/j.ocecoaman.2012.11.006.
41. Pledger S, Pollock KH, Norris JL (2010) Open capture-recapture models with heterogeneity: II. Jolly-Seber model. Biometrics 66(3): 883-890.

42. Laroche KA, Kock AA, Dill LD, Oosthuizen WH (2007) Effects of provisioning ecotourism activity on the behaviour of white sharks Carcharodon carcharias. Mar Ecol Prog Ser 338: 199-209.

43. Ocearch Shark Tracker. Available: sharks-ocearch.vertite.com. Accessed 2013 May 08.

44. Dudley SFJ, Simpfendorfer CA (2006) Population status of 14 shark species caught in the protective gillnets off KwaZulu-Natal beaches, South Africa, 1978-2003. Mar Freshw Res 57(2): 225-240. 